\title{
Analysis of Shear Characteristics of Deep, Anchored Rock Mass under Creep Fatigue Loading
}

\author{
Xiaofeng Li $(\mathbb{D})$ and Zhixiang Yin \\ Department of Civil Engineering, Liaoning Technical University, Fuxin 123000, China \\ Correspondence should be addressed to Xiaofeng Li; lixiaofeng19902021@163.com
}

Received 29 June 2021; Revised 26 July 2021; Accepted 13 August 2021; Published 19 August 2021

Academic Editor: Jianping Sun

Copyright (C) 2021 Xiaofeng Li and Zhixiang Yin. This is an open access article distributed under the Creative Commons Attribution License, which permits unrestricted use, distribution, and reproduction in any medium, provided the original work is properly cited.

\begin{abstract}
To study the influence of earthquakes and engineering disturbances on the deformation of deeply buried rock masses, shear tests were carried out on anchored sandstone rock masses, anchored marble rock masses, and anchored granite rock masses under creep fatigue loading, and a new creep fatigue model was established to characterize the deformation characteristics of anchored rock masses under creep fatigue loading. The creep fatigue curves of different lithologies clearly show three stages: creep attenuation, steady-state creep, and accelerated creep. Fatigue loading can increase the creep of anchored specimens, and the lower the rock strength is, the higher the creep variable under fatigue loading is. However, for the same rock strength, with the increase in load level, the creep variable produced by creep fatigue load presents a linear downward trend. Considering the changes in the mechanical properties of the anchored rock mass under creep fatigue loading, the creep fatigue model of anchored rock masses is established by introducing a function of the fatigue shear modulus, and the accuracy and applicability of the model are verified by laboratory creep fatigue test data. The model provides a theoretical basis for the study of anchored rock mass support under lowfrequency earthquakes or blasting loads.
\end{abstract}

\section{Introduction}

In the construction of strategic projects in large-scale deep rock masses in China, the safety and stability of underground engineering are of great importance. Complex engineering geological environments have presented many challenges in the development of underground engineering [1-3]. For example, the engineering construction of the Sichuan-Tibet railway is particularly challenging because the railway corridor is formed under the coupling effect of structural activity, geomorphic uplift, climate change, and engineering disturbance $[4,5]$. The structural deformation, rock mass loosening, surface freeze-thaw, and engineering disturbance in the shallow crust along the corridor have a profound impact on the stability of the geological body, engineering geological body, engineering rock soil mass, and engineering structure body in the corridor area. The Sichuan-Tibet railway passes through complex geological structures [6-8].
Scholars in China and abroad have performed a considerable amount of research on the shear creep of rock. Liu $[9,10]$ took the shear creep characteristics of mica schist as a research object and discussed the variation law of the radial displacement of mica schist with time determined from the results of the indoor shear creep tests of mica schist. To study the shear creep characteristics of marble with structural planes, He et al. [11] carried out a series of shear creep tests on two kinds of marble with weak and hard structural planes. To study the influence of weak intercalation on the long-term stability of geological bodies, Yao et al. [12] proposed a new unsteady fractal differential creep (UFDC) model based on fractal derivative theory and the results of circumferential shear creep tests of weak interlayers to effectively explain the creep deformation of soft interlayers. Zhang et al. [13] carried out a series of shear creep tests of serrated structural planes under various pore water pressures to explore the influence of pore water pressure on the shear creep characteristics of rock mass discontinuities. 
Additionally, experts have carried out corresponding research on the rheological properties of rocks under different conditions. Wu et al. [14] conducted shear creep tests on fractured mudstone to study the influence of normal stress and precut fracture length on the shear creep characteristics of mudstone. Because most creep models cannot accurately describe the nonlinear creep behavior of mudstone, an improved time-varying creep model was proposed. Zhang et al. [15] carried out creep tests of mudstone under different loading modes and water contents and established an appropriate creep model. Zhang et al. [16] carried out shear creep tests on samples after different numbers of freeze-thaw cycles to study the influence of freeze-thaw cycling on the shear creep characteristics of rock. Chen et al. [17] carried out a series of long-term creep tests of clay rock under different confining pressures and deviatoric stresses under complex conditions of thermal-fluid-mechanical coupling. Xu et al. [18] carried out a series of shear creep tests on rocks with discontinuities to simulate the initiation and propagation of cracks under the action of continuous shear stress and normal stress. Jia et al. [19] carried out shear creep tests on structural plane faults and established a corresponding creep formula.

The above research mainly analyzes the rock mass from the aspects of freeze-thaw cycles and structural planes. Research on the influence of fatigue loads caused by lowfrequency earthquakes or blasting on the rheological properties of rock is relatively limited, while the occurrence frequency of low-frequency earthquakes in actual geotechnical engineering is relatively high, and the impact on geotechnical engineering is also important [20-22]. Earthquakes occur frequently along the Sichuan-Tibet railway, and fault and fracture zones are relatively dense. Earthquakes and engineering blasting result in both dynamic and cyclic loads that are described as low-cycle fatigue loads $[23,24]$. There are many joints and fissures in the deep surrounding rock roadway, which will affect the stability of the rock mass. The rock mass needs to be supported by anchor bolt, anchor cable, or grouting. When the surrounding rock mass is excavated by blasting, it will have a certain impact on the stability of the above anchored rock mass, and the deformation and failure of the deep rock mass is mainly shear creep; therefore, this paper uses indoor test to explore the influence of blasting, excavation, and other disturbance loads on the mechanical properties and stability of anchored rock mass. Based on the above engineering background, to study the shear characteristics of deep anchored jointed rock masses under creep fatigue loading, the deformation characteristics of anchored rock masses under creep fatigue loading under different rock strengths are analyzed through laboratory tests. Based on the change in shear modulus under fatigue loading, a constitutive model reflecting creep fatigue loading is constructed, and the accuracy of the model is verified. This model can comprehensively explain the shear failure characteristics and anchoring mechanism of anchored jointed rock masses under complex stress paths and provide a reference for the study of deep rock mass disaster prevention and safety production.

\section{Creep Fatigue Testing}

2.1. Specimen Preparation. The test rock samples include anchored sandstone rock masses, anchored marble rock masses, and anchored granite rock masses, and the test pieces are all $100 \mathrm{~mm} \times 100 \mathrm{~mm} \times 100 \mathrm{~mm}$ cubes. The size of the test pieces conforms to the relevant provisions of the test specifications of the International Society of Rock Mechanics [25]. The steps followed to prepare the test pieces are as follows:

(1) Rock Block Processing. A massive rock mass is selected, a rock cutter is used to process the rock block into a $100 \mathrm{~mm} \times 100 \mathrm{~mm} \times 50 \mathrm{~mm}$ rock mass, and a drilling machine is used to drill a hole with a diameter of $10 \mathrm{~mm}$ and length of $50 \mathrm{~mm}$ from the center of a side with dimensions of $100 \mathrm{~mm} \times 100 \mathrm{~mm}$ (for the anchor rod).

(2) Rock Block Bonding. The joints are used to bond the upper and lower plates of the rock block. A joint is made by pouring cement mortar into a cuboid of $100 \mathrm{~mm} \times 100 \mathrm{~mm} \times 5 \mathrm{~mm}$ space (the joint thickness is $5 \mathrm{~mm}$ ). The joint mix ratio is cement: river sand: water $=1: 1.5: 0.8$. The test materials are 42.5 ordinary silicate cement and medium-grained sand. The joint shape, size, and material distribution are checked during the test. The test block shall be bonded with cement mortar and placed in the curing box for curing for $28 \mathrm{~d}$.

(3) Installation of the Anchor Rod. HRB335 steel with a yield strength of $335 \mathrm{MPa}$ is selected as the anchor material. A steel bar with a diameter of $6 \mathrm{~mm}$ is placed in the hole in the test piece. The overall length of the reinforcement is $110 \mathrm{~mm}$. The exposed end of the ribbed steel bar is machined to a length of $10 \mathrm{~mm}$, and $50 \mathrm{~mm}$ extends into the test piece, through both the upper and lower walls. Grouting is used to fill the holes and reinforce the anchor rod. The grouting material is the same as the joint material. Anchor the test piece with anchor bolt and put it into the curing box for curing for $28 \mathrm{~d}$.

An anchored rock mass fabricated according to the above steps is shown in Figure 1.

The test loading system adopts the cutting equipment of the TAW-2000 triaxial testing servo apparatus of the civil engineering test center of Liaoning University of Engineering and Technology, as shown in Figure 2. It is mainly composed of a loading system, measuring system, and controller. Fully automatic control is achieved by microcomputer-controlled electrohydraulic servo valve loading and manual hydraulic loading. The host machine and the control cabinet are separate. The testing machine uses sensors to measure force, and the host machine automatically collects stress data and displacement. The resulting test curves and test results have high reliability.

\subsection{Test Scheme and Steps}

2.2.1. Test Scheme. Before the test, it was necessary to determine the basic mechanical parameters, such as 


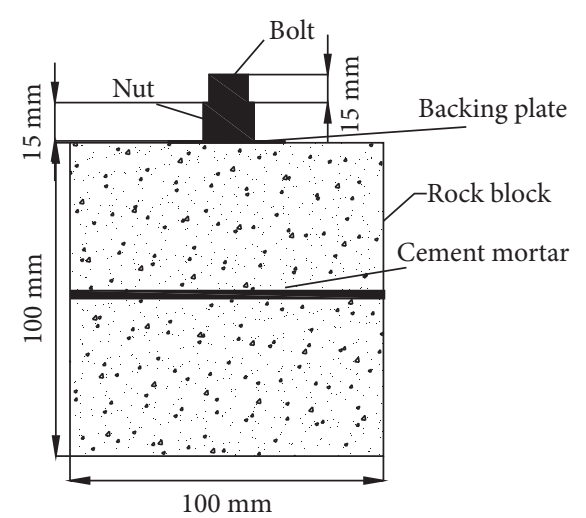

(a)

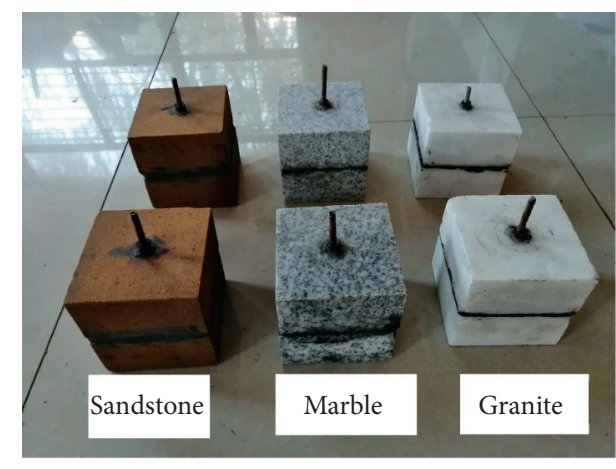

(b)

Figure 1: Test pieces. (a) Specimen model diagram. (b) Physical drawing of the specimen.

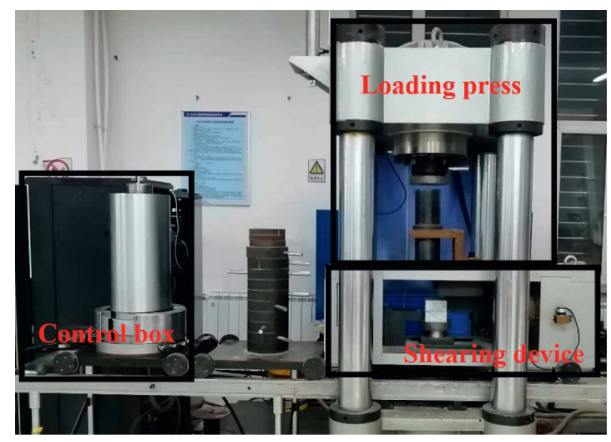

Figure 2: Shearing device.

compressive strength, tensile strength, and elastic modulus, of the three rock materials. The basic mechanical parameters of the three kinds of rocks were determined by uniaxial compression tests and Brazilian splitting tests [26,27], and the details are shown in Table 1. The mechanical parameters of anchored jointed rock mass are summarized in Table 2.

The basis for selecting loading parameters is as follows: according to relevant reference [28], the maximum peak velocity of underground vibration is $0.52 \sim 4.38 \mathrm{~m} / \mathrm{s}$, the frequency range is $0.01 \sim 0.1 \mathrm{~Hz}$, the shear wave velocity is $2480 \mathrm{~m} / \mathrm{s}$, and the longitudinal wave velocity is $4300 \mathrm{~m} / \mathrm{s}$. Therefore, during these tests, the loading rate was set to $200 \mathrm{~N} / \mathrm{s}$, the fatigue load was set to $\pm 5 \mathrm{kN}$ on the basis of all levels of loading, and the shear stress was set to $\pm 0.5 \mathrm{MPa}$. The load amplitude was 1/10-1/100 of the compressive strength. The specific test scheme is shown in Figure 3.

2.2.2. Test Procedure. The creep fatigue testing was carried out by graded loading, to approximately $20 \%, 40 \%, 60 \%$, and $80 \%$ of the compressive strength of the specimen, i.e., $2 \mathrm{MPa}$, $4 \mathrm{MPa}, 6 \mathrm{MPa}$, and $8 \mathrm{MPa}$. The three-dimensional stress states of rock mass are as follows: there are rightward stresses in the upper left and right directions of the specimen. There is a right stress at the lower left of the specimen; a left stress at the lower right of the specimen; and no stress in other directions. This test is an unconfined shear test, and the relevant test steps are as follows:

(1) Application of Shear Stress. The specimen is put into the shear device, and then the load is controlled at a rate of $0.5 \mathrm{MPa} / \mathrm{s}$ to the specified shear stress, which is then maintained.

(2) Application of Fatigue Load. When the shear stress of each level is applied for approximately $59 \mathrm{~h}$, load control is adopted, and fatigue loading is applied at a rate of $200 \mathrm{~N} / \mathrm{s}$. Before and after the fatigue loading is applied, the pressure is stabilized for a certain period, and the internal stress of the specimen is adjusted to make the conditions more accurately match those encountered in engineering practice. The test is carried out according to the above steps until the specimen is damaged.

(3) Reading Data. The shear creep values are read at intervals of $5 \mathrm{~min}, 10 \mathrm{~min}, 20 \mathrm{~min}, 40 \mathrm{~min}, 1 \mathrm{~h}, 2 \mathrm{~h}$, $4 \mathrm{~h}, 8 \mathrm{~h}$, and $12 \mathrm{~h}$ during the creep attenuation and steady-state creep stages and then read every $12 \mathrm{~h}$ until the end of the test. During the fatigue loading stage and creep acceleration stage, the data are read every $0.5 \mathrm{~min}$. The condition for the stability of the shear creep deformation of a rock mass is a creep rate increment $\leq 5 \times 10^{-4} \mathrm{~mm} / \mathrm{D}$ [29]. 
TABLE 1: Conventional mechanical parameters of the rock mass.

\begin{tabular}{lcccccc}
\hline Rock & $\begin{array}{c}\text { Compressive strength } \\
(\mathrm{MPa})\end{array}$ & $\begin{array}{c}\text { Tensile strength } \\
(\mathrm{MPa})\end{array}$ & $\begin{array}{c}\text { Elastic modulus } \\
(\mathrm{GPa})\end{array}$ & $\begin{array}{c}\text { Poisson's } \\
\text { ratio }\end{array}$ & $\begin{array}{c}\text { Cohesion } \\
(\mathrm{MPa})\end{array}$ & $\begin{array}{c}\text { Internal friction angle } \\
\left({ }^{\circ}\right)\end{array}$ \\
\hline Sandstone & 30.20 & 1.42 & 7.83 & 0.31 & 8.11 & 35.12 \\
Marble & 110.70 & 3.79 & 20.20 & 0.28 & 15.12 & 33.50 \\
Granite & 120.23 & 4.11 & 23.10 & 0.22 & 14.13 & 45.03 \\
\hline
\end{tabular}

TABLE 2: Mechanical parameters of anchored jointed rock mass.

\begin{tabular}{|c|c|c|c|c|}
\hline Rock specimen & Compressive strength $(\mathrm{MPa})$ & Shear strength $(\mathrm{MPa})$ & Elastic modulus (GPa) & Poisson's ratio \\
\hline Anchored sandstone rock masses & 21.30 & 9.26 & 6.12 & 0.22 \\
\hline Anchored marble rock masses & 72.45 & 10.06 & 15.47 & 0.17 \\
\hline Anchored granite rock masses & 84.21 & 10.15 & 16.38 & 0.12 \\
\hline
\end{tabular}

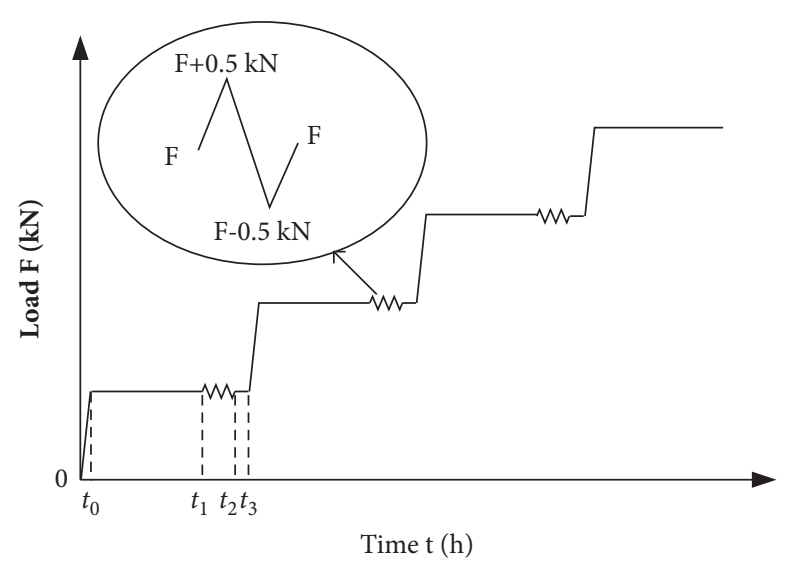

FIGURE 3: Loading path diagram. $0-t_{0}$ is the loading time before reaching the specified load; $t_{0}-t_{1}$ is the specified load stabilization time; $t_{1}-t_{2}$ is the fatigue load application time; and $t_{2}-t_{3}$ is the stability time after the fatigue load is applied.

\section{Analysis of the Creep Fatigue Curves}

3.1. Analysis of the Test Curves. To explore the shear mechanical properties of different rock strengths under creep fatigue loading, typical test data were selected to draw the curves of strain and stress with time for the different rock types, as shown in Figure 4.

Due to the different rock strengths, the test curves measured during the creep fatigue loading tests are different, but they all have three typical stages, namely, a creep attenuation stage, a steady-state creep stage, and an accelerated creep stage. When a specimen is in the steady-state stage, with the application of fatigue loading, the creep curve will fluctuate to a certain extent; that is, with the increase or decrease in stress, the creep curve will fluctuate. The results show that the change in the shear strain lags behind the change in the shear stress, which indicates that the rock has an elastic aftereffect. The steady creep curve of each stage is amplified to some extent compared with that before the fatigue loading is applied, which is due to the microcracks present in each specimen during the steady-state stage, causing the rock to crack under the action of fatigue loading. As a result, the deformation of a specimen is greater after fatigue loading is applied.

\subsection{Creep Analysis}

3.2.1. Creep Deformation. To quantitatively analyze the influence of fatigue loading on shear creep at all levels, the steady creep variables of each stage under different rock strengths are determined, as shown in Figure 5.

$$
y=M+N * x
$$

In this formula, $M$ and $N$ are the relevant parameters of the formula, $x$ is the load level, and the relevant fitting parameters are shown in Table 3.

The creep variable increases with the grading under different rock strengths. The creep variables ordered from large to small correspond to anchored sandstone rock masses, anchored marble rock masses, and anchored granite rock masses, and the coefficient of fit is higher than 0.95 . This finding indicates that the creep and grading show a linear relationship under different rock strengths; in formula (1), $M$ is the intercept of the fitting formula on the $y$-axis, which is defined as the instantaneous creep intercept, which can characterize the instantaneous creep of the specimen, and the order of the sizes of the instantaneous creep intercepts under the different rock strengths is anchored sandstone rock masses $>$ anchored marble rock masses $>$ anchored 


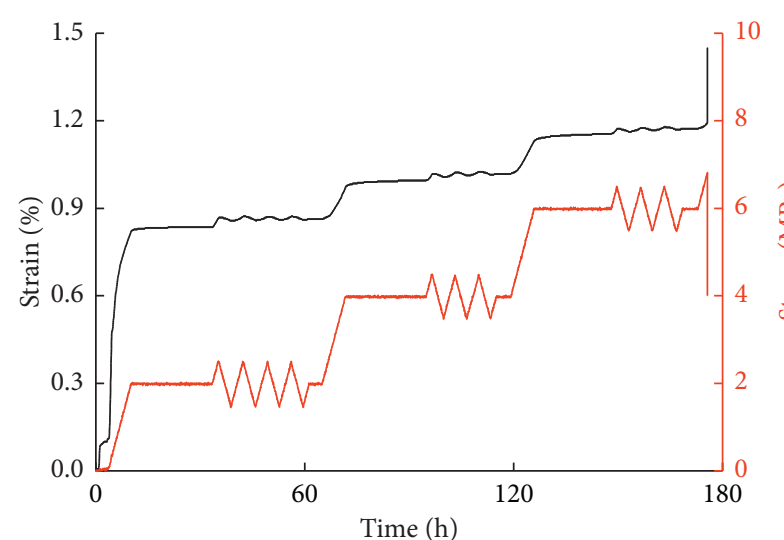

- Strain-time curve

_ Stress-time curve

(a)

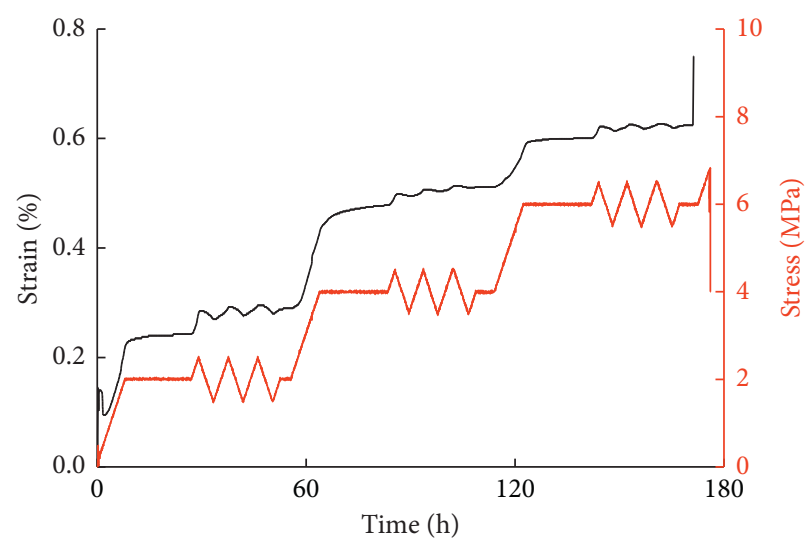

- Strain-time curve

— Stress-time curve

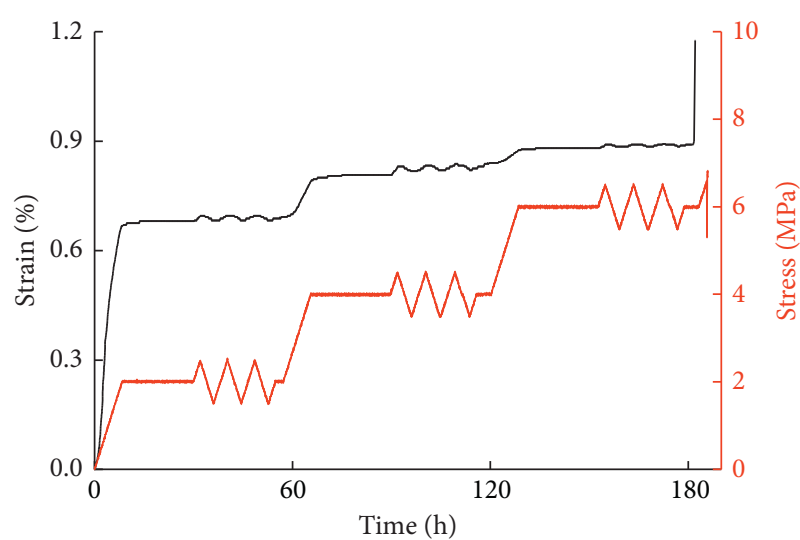

- Strain-time curve

- Stress-time curve

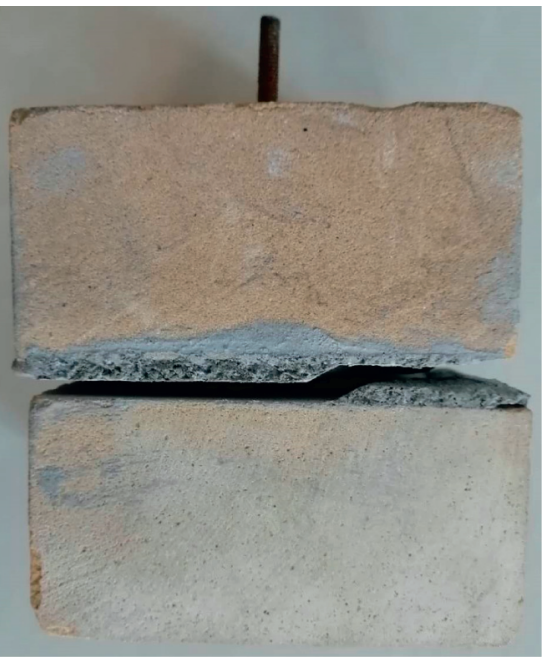

(d)

FIGURE 4: Time-dependent curves of strain and stress under different rock strengths and failure specimen. (a) Anchored sandstone rock masses. (b) Anchored marble rock masses. (c) Anchored granite rock masses. (d) Failure specimen.

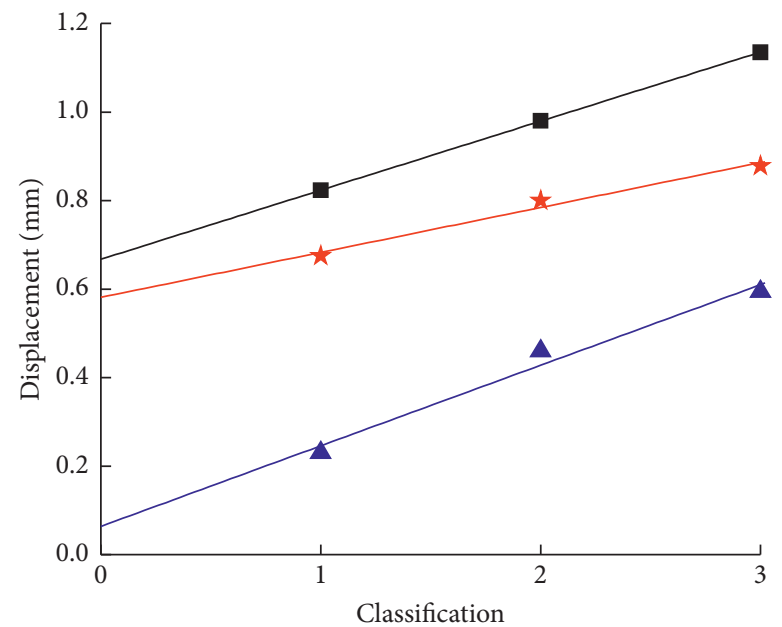

- Sandstone

$\star$ Marble

- Granite

Figure 5: Fitting curve of creep at different stages. 
TABLE 3: Related parameters of the fitting curve.

\begin{tabular}{lccc}
\hline Rock specimen & $M$ & $N$ & $R^{2}$ \\
\hline Anchored sandstone rock masses & 0.667 & 0.156 & 1 \\
Anchored marble rock masses & 0.581 & 0.102 & 0.965 \\
Anchored granite rock masses & 0.064 & 0.182 & 0.955 \\
\hline
\end{tabular}

granite rock masses. The higher the rock strength is, the stronger its ability to resist shear deformation and the lower the instantaneous creep; consequently, the instantaneous creep intercept $M$ is smaller. $N$ is the slope of the fitting formula (1) and represents the initial creep rate in the steadystate phase. The larger $N$ is, the faster the change in the initial creep in the steady-state stage is; the corresponding order is anchored granite rock masses $>$ anchored sandstone rock masses $>$ anchored marble rock masses. Since the change in creep during the steady-state stage is small, the deformation of a rock specimen in the steady-state stage can be quantitatively reflected by the change in $N$.

3.2.2. Creep Fatigue Increment. To study the influence of fatigue loading on the shear creep deformation of rock specimens at all levels of loading, the creep variables before and after the application of fatigue loads are summarized and plotted, as shown in Figure 6. The changes in creep increment during different stages before and after fatigue loading are plotted as shown in Figure 7.

The creep variables before and after fatigue at all levels of loading follow the order of anchored sandstone rock masses $>$ anchored marble rock masses $>$ anchored granite rock masses, which indicates that the creep variables under shear loads of different rock strengths are different. The lower the rock strength is, the larger the creep variable is, and vice versa. From the results of the creep increment before and after fatigue loading is applied at all levels, the overall creep variable decreases with increasing load level, indicating that the creep increment increases. The results show that the sensitivity of fatigue loading to shear creep decreases with the increase in load level, which is due to the increase in shear stress, leading to further compaction of the specimen and a decrease in the creep variable. Compared with the incremental change in the anchored sandstone rock masses, the incremental changes in the anchored marble rock masses and anchored granite rock masses have larger ranges, indicating that the influence of fatigue loading on the deformation of high-strength rock is more obvious than that on weak rock.

3.3. Shear Modulus. As a variable describing the inherent properties of rock, the shear modulus is often used to characterize the change in rock strength [30,31]. To explore the effect of fatigue loading on the shear modulus of the specimen, the shear modulus change curve with time throughout the creep process is drawn, as shown in Figure 8. The shear modulus is solved by equation (2), where $E$ is the elastic modulus, which is solved by the ratio of shear stress and longitudinal strain in the stress-strain curve, $v$ is the Poisson ratio, which is solved by the ratio of transverse strain

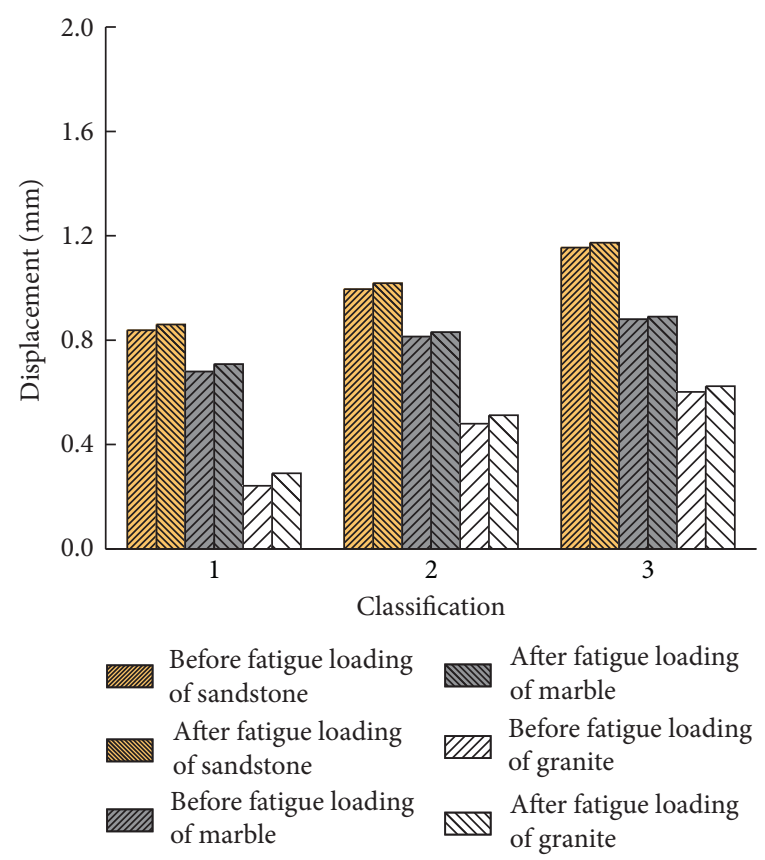

FIgURE 6: Bar chart of creep before and after fatigue loading.

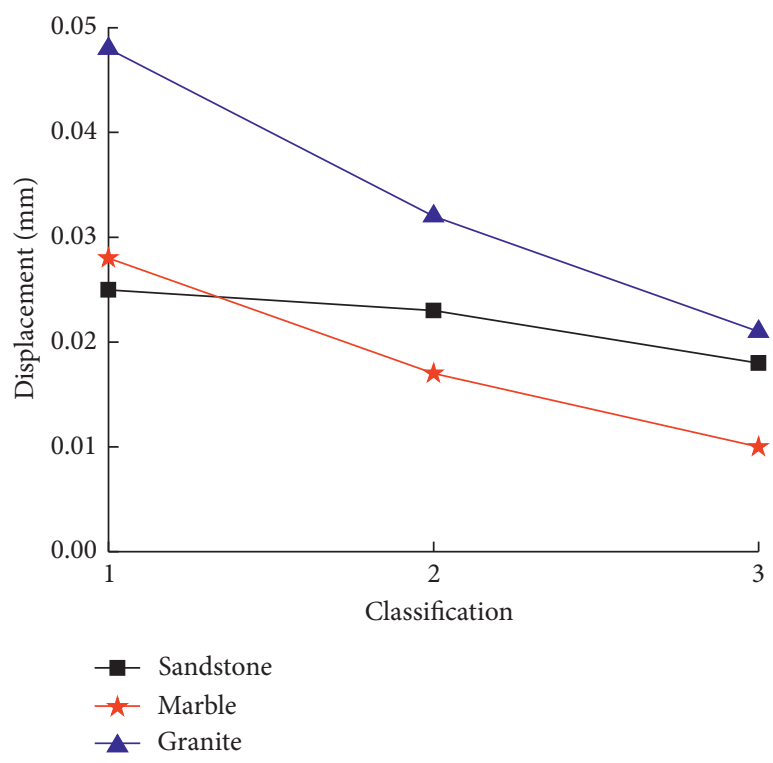

Figure 7: Creep increment curve before and after fatigue loading.

and longitudinal strain, in which the longitudinal strain is the strain in the stress-strain curve, and the transverse strain is monitored by the strain collector.

$$
G=\frac{E}{2(1+v)},
$$

where $G$ is the shear modulus; $E$ is the elastic modulus; and $v$ is the Poisson ratio.

Figure 8 shows that the shear modulus changes piecewise with time. Before the fatigue load is applied, the curve changes approximately linearly, while after the fatigue load is 


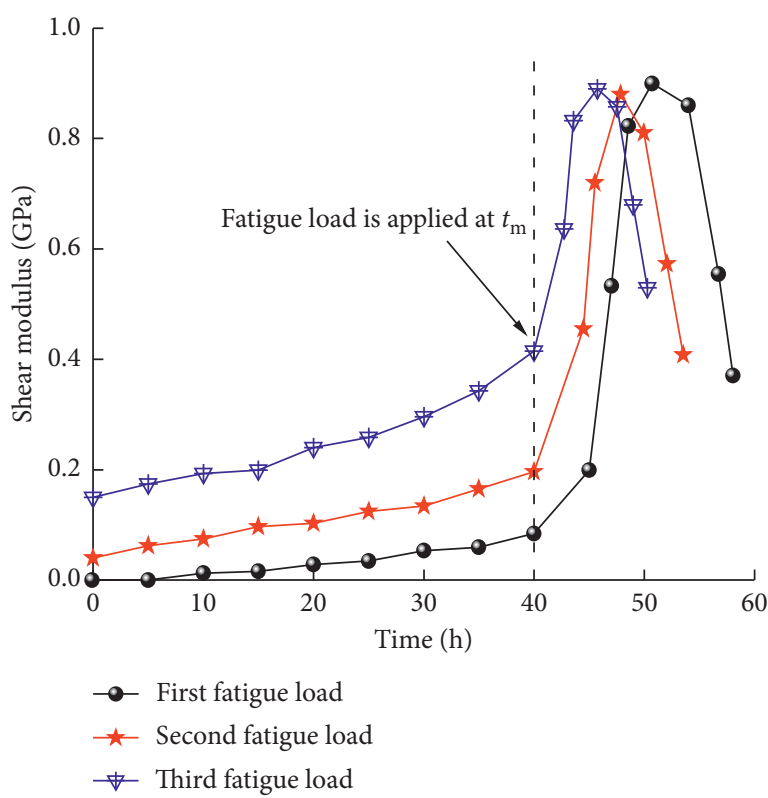

(a)

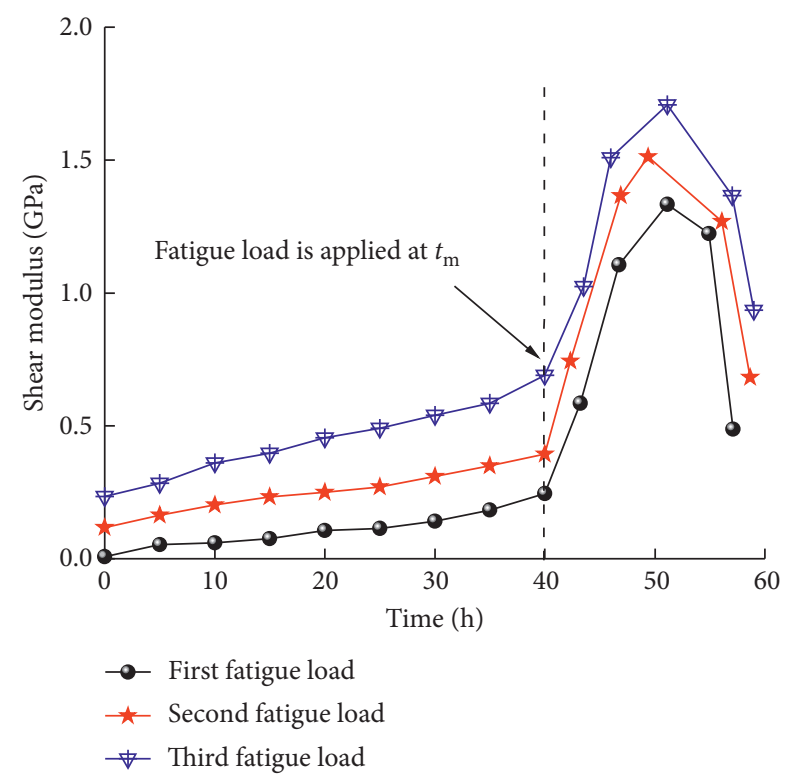

(b)

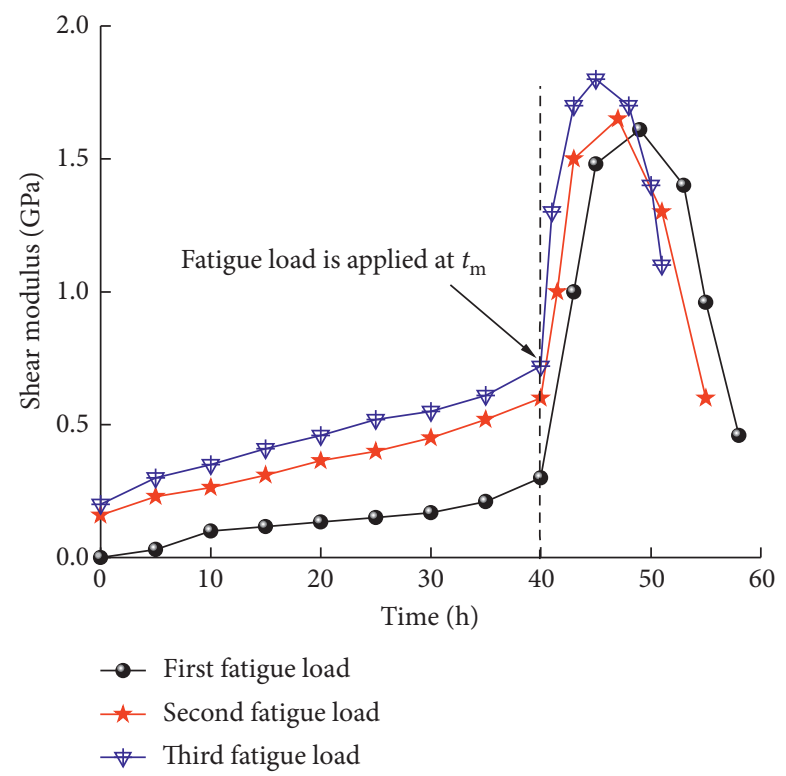

(c)

FIgURE 8: Shear modulus versus time curve. (a) Anchored sandstone rock masses. (b) Anchored marble rock masses. (c) Anchored granite rock masses.

applied, the curve shows a nonlinear change trend, which is represented by a piecewise function:

$$
G\left(t-t_{m}\right)=\left\{\begin{array}{ll}
a_{1} t+b_{1} & \left(t \leq t_{m}\right) \\
a_{2} t^{2}+b_{2} t+c & \left(t>t_{m}\right)
\end{array},\right.
$$

where $G_{1}\left(t-t_{\mathrm{m}}\right)$ is the function of fatigue shear modulus; $t_{\mathrm{m}}$ is the initial moment of fatigue load application, which is $40 \mathrm{~h} ; a_{1}$ and $b_{1}$ are the coefficients of the firstorder function; and $a_{2}, b_{2}$, and $c$ are the coefficients of the quadratic function. Regression analysis of equation (3) is carried out using the data in Figure 8, as shown in Table 4.

\section{Creep Fatigue Modeling}

4.1. Creep Model. The creep curve of a rock mass mainly includes three stages $[32,33]$. The model of a combination of elastic elements, viscoelastic elements, and viscoplastic elements in series is often used to describe the creep attenuation and steady-state creep stages [34]. The rheological properties of Nishihara model under low stress conditions are also more comprehensive, which can better describe the attenuation and stability stage of rock creep, and have relaxation characteristics. The rheological properties of Nishihara model are closer to those of the actual rock mass [35]. The creep model is shown in Figure 9 [36, 37]. 
TABLE 4: Related parameters of fitting curve.

\begin{tabular}{|c|c|c|c|c|c|c|c|c|}
\hline \multirow{2}{*}{ Rock specimen } & \multirow{2}{*}{ Load level } & \multicolumn{3}{|c|}{ First-order function } & \multicolumn{4}{|c|}{ Quadratic function } \\
\hline & & $a_{1}$ & $b_{1}$ & $R_{1}{ }^{2}$ & $a_{2}$ & $b_{2}$ & C & $R_{2}^{2}$ \\
\hline \multirow{3}{*}{ Anchored sandstone rock masses } & 1 & 0.02 & -0.09 & 0.94 & -0.02 & 1.60 & -40.69 & 0.98 \\
\hline & 2 & 0.03 & 0.39 & 0.97 & -0.02 & 2.03 & -48.55 & 0.90 \\
\hline & 3 & 0.06 & 0.13 & 0.93 & -0.02 & 1.95 & -44.03 & 0.90 \\
\hline \multirow{3}{*}{ Anchored marble rock masses } & 1 & 0.01 & 0.01 & 0.93 & -0.02 & 1.72 & -41.91 & 0.80 \\
\hline & 2 & 0.01 & 0.13 & 0.98 & -0.01 & 1.25 & -29.96 & 0.95 \\
\hline & 3 & 0.01 & 0.24 & 0.99 & -0.01 & 1.29 & -31.10 & 0.94 \\
\hline \multirow{3}{*}{ Anchored granite rock masses } & 1 & 0.01 & 0.01 & 0.93 & -0.01 & 1.46 & -34.14 & 0.94 \\
\hline & 2 & 0.01 & 0.16 & 0.99 & -0.02 & 1.61 & -36.34 & 0.89 \\
\hline & 3 & 0.01 & 0.22 & 0.98 & -0.02 & 2.27 & -50.00 & 0.98 \\
\hline
\end{tabular}

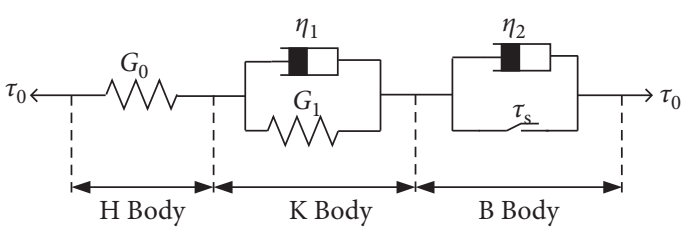

Figure 9: Shear creep model.

In Figure 9, $G_{0}$ is the instantaneous shear modulus, $G_{1}$ is the viscoelastic shear modulus, and $\eta_{1}$ and $\eta_{2}$ are the viscosity coefficients, which indicate that the speed of the rheological change is stable. The smaller the value of a viscosity coefficient is, the shorter the time to reach stability. $\tau_{s}$ is the yield shear stress or long-term shear strength; $\tau_{0}$ is the shear stress.

Considering the actual stress of the rock mass, the model was modified as follows:

(1) The above analysis shows that the creep attenuation stage has obvious nonlinear characteristics and that the Kelvin model cannot describe the creep attenuation stage of rock. Considering the time correlation of the viscosity coefficient in the Kelvin model, assuming that the coefficient satisfies the power function relationship with time in the creep process, the nonlinear Kelvin viscoelastic model is established.

(2) To satisfy the shear rheological properties of specimens under fatigue loading, a modified nonlinear Kelvin model is obtained by introducing the fatigue shear modulus function $G_{1}\left(t-t_{\mathrm{m}}\right)$.

(3) When the stress level imposed by the creep test is higher than the long-term strength, body B plays a role. The steady-state stage can be described as a stable creep stage, but the unstable creep stage and accelerated creep stage cannot be well described. This problem can be solved by connecting a nonlinear rheological element $E$ with the time factor in series.

The nonlinear characteristics of the acceleration element are particularly obvious. The accelerated creep stage of rock is the nonlinear acceleration change of rock. Using this element can better characterize the acceleration stage of rock. The model of body $E$ is shown in Figure 10 $[38,39]$.where $G_{2}$ and $n$ are model parameters, $\gamma$ is the

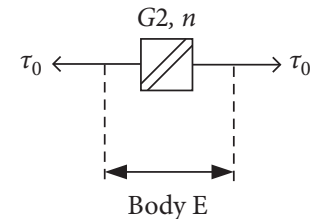

Figure 10: Model of body $E$.

shear strain, $t_{2}$ is the start time of the acceleration stage, and $t_{3}$ is the end time of the acceleration stage.

$$
\gamma=\left\{\begin{array}{ll}
0 & \left(t \leq t_{2}\right) \\
\frac{\tau_{0}}{G_{2}}\left\{1-\exp \left[-\left(\frac{t-t_{2}}{t_{3}-t_{2}}\right)^{n}\right]\right\} & \left(t>t_{2}\right)
\end{array},\right.
$$

4.2. Creep Fatigue Model. The creep fatigue model is shown in Figure 11 [40]. The corresponding creep equations are obtained as follows.

In this figure, $\lambda$ is a constant, and $G_{1}\left(t-t_{\mathrm{m}}\right)$ is a function of the viscoelastic fatigue shear modulus varying with time.

The total shear creep strain $\gamma$ satisfies $[41,42]$

$$
\gamma=\gamma_{\mathrm{H}}+\gamma_{\mathrm{K}}+\gamma_{\mathrm{B}}+\gamma_{\mathrm{E}}
$$

where $\gamma_{\mathrm{H}}$ is the elastic shear strain; $\gamma_{\mathrm{K}}$ is the viscoelastic shear strain; $\gamma_{\mathrm{B}}$ is the viscoplastic shear strain; and $\gamma_{\mathrm{gE}}$ is the nonlinear shear strain.

(1) The creep equation of the elastic element is

$$
\gamma_{\mathrm{H}}=\frac{\tau_{0}}{G_{0}} \text {. }
$$

(2) The creep equation of the elastic viscous element is

$$
\gamma_{\mathrm{K}}=\frac{\tau_{0}}{G_{1}\left(t-t_{m}\right)}\left[1-\exp \left(-\frac{G_{1}\left(t-t_{m}\right)}{\eta_{1} \lambda} t^{\lambda}\right)\right] \text {. }
$$

(3) The creep equation of viscoplastic components is

$$
\gamma_{\mathrm{B}}=\frac{\tau_{0}-\tau_{\mathrm{S}}}{\eta_{2}} t
$$

(4) The creep equation of acceleration element is 


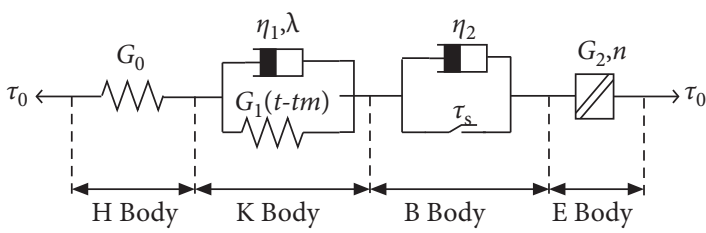

Figure 11: Creep fatigue model.

$$
\gamma_{\mathrm{E}}=\frac{\tau_{0}}{G_{2}}\left\{1-\exp \left[-\left(\frac{t-t_{2}}{t_{3}-t_{2}}\right)^{n}\right]\right\}
$$

The creep equation at different stages is as follows:

(1) When the shear stress level is less than the long-term strength, the creep equation is as follows:

$$
\gamma=\frac{\tau_{0}}{G_{0}}+\frac{\tau_{0}}{G_{1}\left(t-t_{m}\right)}\left[1-\exp \left(-\frac{G_{1}\left(t-t_{m}\right)}{\eta_{1} \lambda} t^{\lambda}\right)\right]
$$

(2) When the shear stress level is higher than the longterm strength but creep has not reached the acceleration stage, the creep equation is as follows:

$$
\gamma=\frac{\tau_{0}}{G_{0}}+\frac{\tau_{0}}{G_{1}\left(t-t_{m}\right)}\left[1-\exp \left(-\frac{G_{1}\left(t-t_{m}\right)}{\eta_{1} \lambda} t^{\lambda}\right)\right]+\frac{\tau_{0}-\tau_{\mathrm{S}}}{\eta_{2}} t
$$

(3) When the shear stress level is higher than the longterm strength and the creep reaches the acceleration stage, the creep equation is as follows:

$$
\gamma=\frac{\tau_{0}}{G_{0}}+\frac{\tau_{0}}{G_{1}\left(t-t_{m}\right)}\left[1-\exp \left(-\frac{G_{1}\left(t-t_{m}\right)}{\eta_{1} \lambda} t^{\lambda}\right)\right]+\frac{\tau_{0}-\tau_{\mathrm{S}}}{\eta_{2}} t+\frac{\tau_{0}}{G_{2}}\left\{1-\exp \left[-\left(\frac{t-t_{2}}{t_{3}-t_{2}}\right)^{n}\right]\right\} .
$$

In conclusion, the shear creep equation under fatigue loading is as follows $[43,44]$ :

$$
\gamma=\left\{\begin{array}{l}
\frac{\tau_{0}}{G_{0}}+\frac{\tau_{0}}{G_{1}\left(t-t_{m}\right)}\left[1-\exp \left(-\frac{G_{1}\left(t-t_{m}\right)}{\eta_{1} \lambda} t^{\lambda}\right)\right]\left(\tau_{0} \leq \tau_{\mathrm{S}}\right) \\
\frac{\tau_{0}}{G_{0}}+\frac{\tau_{0}}{G_{1}\left(t-t_{m}\right)}\left[1-\exp \left(-\frac{G_{1}\left(t-t_{m}\right)}{\eta_{1} \lambda} t^{\lambda}\right)\right]+\frac{\tau_{0}-\tau_{\mathrm{S}}}{\eta_{2}} t\left(\tau_{0}>\tau_{\mathrm{S}}, t \leq t_{2}\right) \\
\frac{\tau_{0}}{G_{0}}+\frac{\tau_{0}}{G_{1}\left(t-t_{m}\right)}\left[1-\exp \left(-\frac{G_{1}\left(t-t_{m}\right)}{\eta_{1} \lambda} t^{\lambda}\right)\right]+\frac{\tau_{0}-\tau_{\mathrm{S}}}{\eta_{2}} t+\frac{\tau_{0}}{G_{2}}\left\{1-\exp \left[-\left(\frac{t-t_{2}}{t_{3}-t_{2}}\right)^{n}\right]\right\}\left(\tau_{0}>\tau_{\mathrm{S}}, t>t_{2}\right)
\end{array}\right.
$$

\section{Model Validation}

To solve the relevant parameters of the creep equation, combined with the creep test data, the mathematical optimization software 1stOpt is used; based on the quasiNewton method and general global optimization method $[45,46]$, the solution method of equation (13) is given under different conditions, as shown in Table 5.
The shear creep model under fatigue loading can be obtained by introducing the relevant parameters in Table 4 into equation (13). Firstly, 1stOpt software is used to identify the parameters in equation (13) of creep fatigue model. Secondly, bring the solved parameters into the creep fatigue model to obtain the equation describing the relationship between rock stress-strain and time. Finally, by giving time to the creep fatigue equation, the corresponding theoretical 
TABle 5: Summary of model parameters.

\begin{tabular}{|c|c|c|c|c|c|c|c|c|c|}
\hline Specimen & Shear stress $(\mathrm{MPa})$ & $G_{0}(\mathrm{GPa})$ & $G_{1}(\mathrm{GPa})$ & $\eta_{1}(G P a \cdot h)$ & $\eta_{2}(\mathrm{GPa} \cdot \mathrm{h})$ & $\lambda$ & $G_{2}(\mathrm{GPa})$ & $n$ & $R^{2}$ \\
\hline \multirow{4}{*}{ Anchored sandstone rock masses } & 2 & 1.47 & 23.41 & 11.54 & 0.21 & 0.74 & - & - & 0.978 \\
\hline & 4 & 1.22 & 20.17 & 10.13 & 1.42 & 0.82 & - & - & 0.976 \\
\hline & 6 & 0.99 & 18.52 & 9.77 & 0.63 & 0.91 & - & - & 0.964 \\
\hline & 6.5 & 0.86 & 15.44 & 8.12 & 0.77 & 0.21 & 10.04 & 0.58 & 0.951 \\
\hline \multirow{4}{*}{ Anchored marble rock masses } & 2 & 0.73 & 14.97 & 7.46 & 0.84 & 0.44 & - & - & 0.981 \\
\hline & 4 & 2.31 & 34.22 & 16.52 & 1.09 & 0.56 & - & - & 0.972 \\
\hline & 6 & 2.14 & 30.56 & 12.44 & 1.54 & 0.84 & - & - & 0.966 \\
\hline & 6.4 & 1.98 & 28.94 & 10.12 & 0.13 & 0.11 & 15.43 & 0.66 & 0.944 \\
\hline \multirow{4}{*}{ Anchored granite rock masses } & 2 & 1.87 & 25.10 & 9.81 & 0.15 & 0.37 & - & - & 0.974 \\
\hline & 4 & 1.74 & 24.13 & 9.54 & 3.11 & 0.59 & - & - & 0.951 \\
\hline & 6 & 0.44 & 47.18 & 19.46 & 2.56 & 0.87 & - & - & 0.948 \\
\hline & 6.6 & 1.12 & 45.69 & 18.57 & 1.69 & 0.14 & 22.16 & 0.74 & 0.936 \\
\hline
\end{tabular}

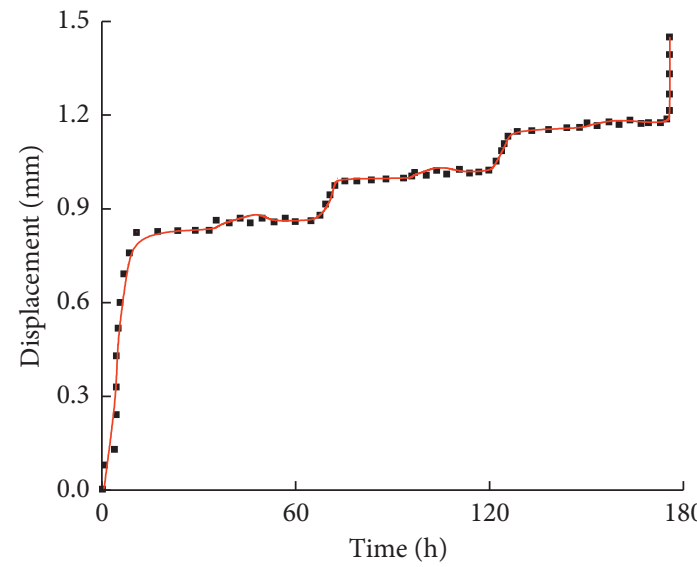

- Experimental data

- Theoretical curve

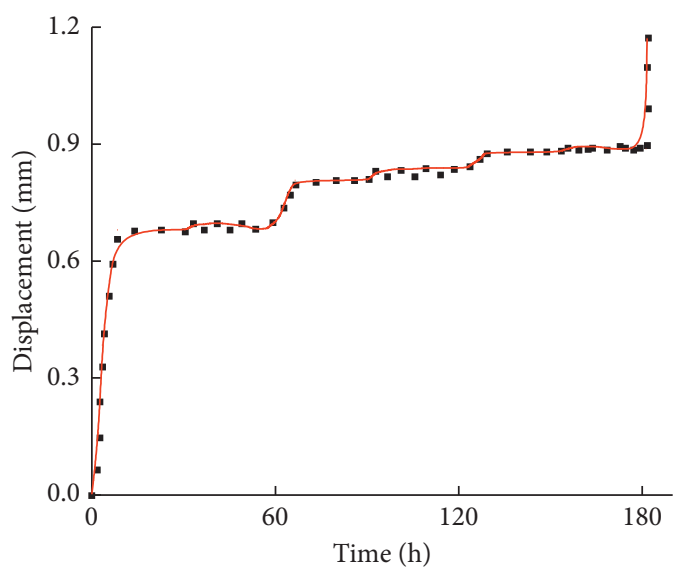

- Experimental data

— Theoretical curve

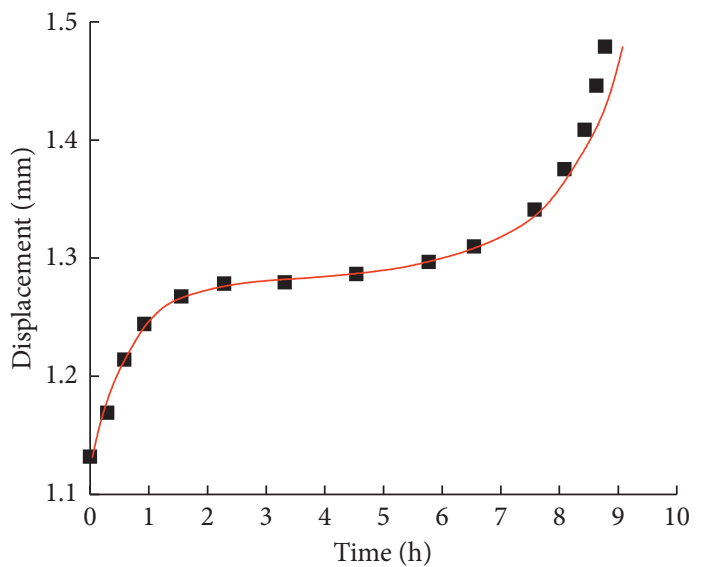

- Experimental data

- Theoretical curve

(a)

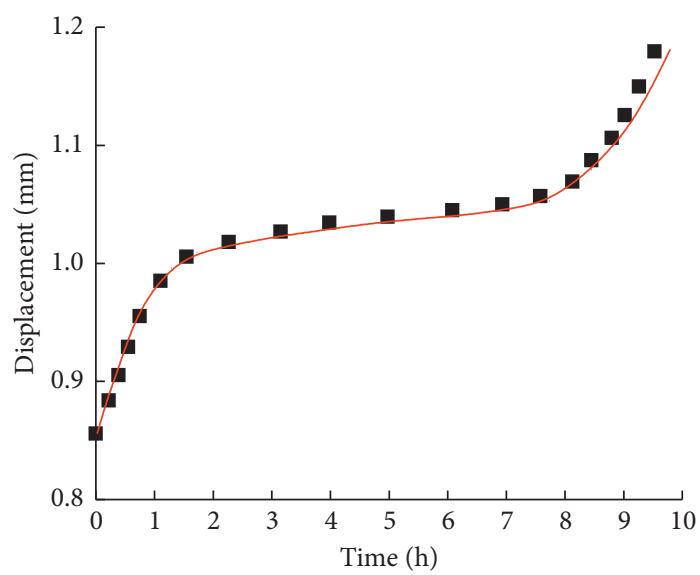

- Experimental data

— Theoretical curve

(b)

FIgURE 12: Continued. 

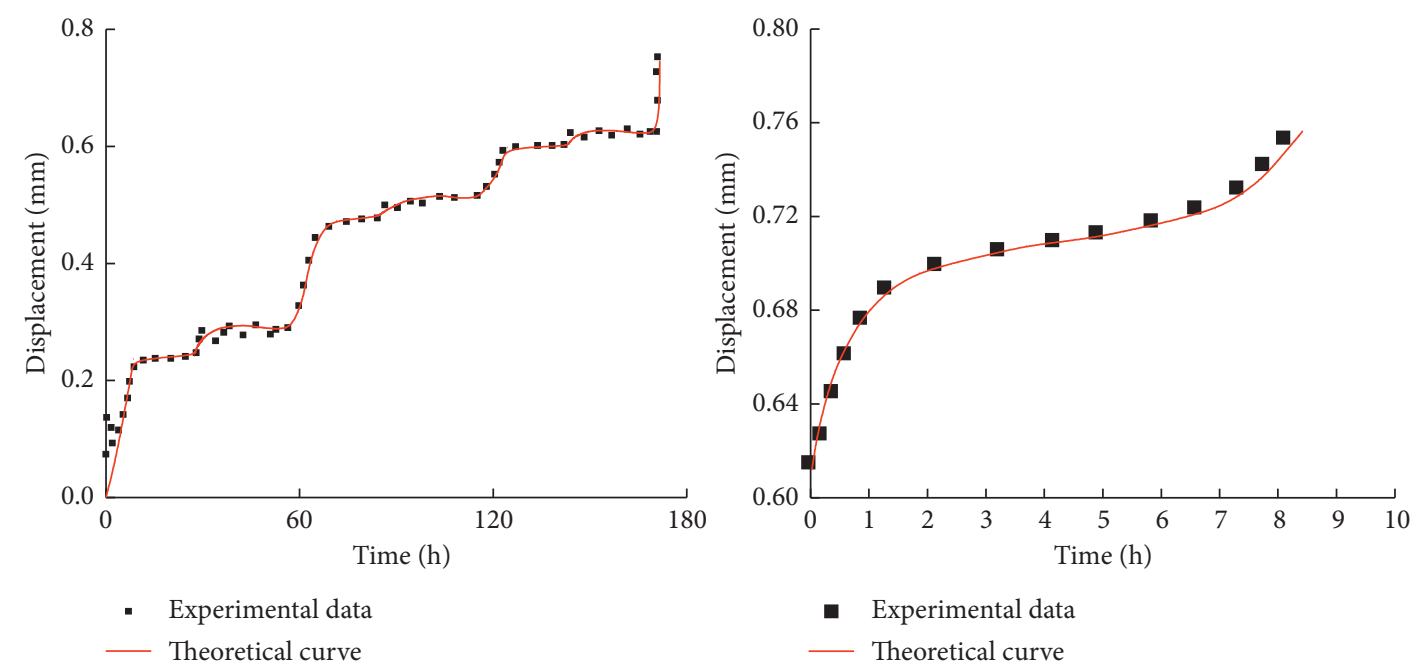

(c)

Figure 12: Comparisons between the experimental data and theoretical curves. (a) Anchored sandstone rock masses. (b) Anchored marble rock masses. (c) Anchored granite rock masses.

displacement value can be obtained. To verify the accuracy of the model, comparison diagrams between the test data and the theoretical curves are drawn, as shown in Figure 12.

The theoretical curves can accurately describe the creep test results and can better describe the resulting fatigue curves. The attenuation stage, stability stage, fatigue stage, and acceleration stage all meet the requirements. Generally, the fitting coefficient is higher than 0.93, indicating that the fitting degree is good, which indicates that the model can accurately reflect the shear mechanical characteristics of anchored rock masses under creep fatigue loading.

\section{Conclusion}

In this paper, through the shear testing of anchored rock masses with different rock strengths under creep fatigue loading, the influence law of fatigue loading on shear creep is explored:

(1) The creep fatigue tests under different rock strengths exhibit typical creep mechanical properties, instantaneous creep, attenuation creep, steady-state creep, and accelerated creep. With increasing specimen strength, the unstable creep stage appears earlier. The creep variable increases with increasing load level under different rock strengths; the creep variable values exhibit the order of anchored sandstone rock masses $>$ anchored marble rock masses $>$ anchored granite rock masses.

(2) By applying fatigue loading during shear creep tests, the resulting creep curve fluctuates to a certain extent; with the increase and decrease in stress, the strain fluctuates, and the fluctuation in strain occurs after the change in stress, which indicates that the change in shear strain lags behind the change in shear stress. The creep increment under fatigue loading presents a decreasing trend with progression of the creep stages, and the sensitivity of fatigue loading to shear creep decreases with the increase in load level.

(3) Considering the influence of fatigue loading on the model parameters, the fatigue shear modulus function is introduced into the Kelvin model and constructed a creep fatigue model. The accuracy of the model is verified by comparing the test data with the theoretical curve, which provides the basis for the support of the surrounding rock cavern under lowfrequency seismic loading.

\section{Data Availability}

The data used to support the findings of this study are available from the corresponding author upon request.

\section{Disclosure}

The authors declare that this paper has been presented as preprint in Research Square.

\section{Conflicts of Interest}

The authors declare that they have no conflicts of interest.

\section{Acknowledgments}

The authors gratefully acknowledge the National Natural Science Foundation of China (51774173) for funding this work. Special thanks are given to Professor Xiangzhi Yin for providing technical support. 


\section{References}

[1] K. Acecr and I. Ahvaz, "Analytical study of common rigid steel connections under the effect of heat," Advances in Civil Engineering, vol. 24, no. 14, pp. 1-10, 2014.

[2] H. H. Titi, N. J. Coley, and V. Latifi, "Evaluation of pavement performance due to overload single trip permit truck traffic in Wisconsin," Advances in Civil Engineering, vol. 28, no. 6, pp. 107-111, 2018.

[3] J. Chen, H. Zhao, F. He, J. Zhang, and K. Tao, "Studying the performance of fully encapsulated rock bolts with modified structural elements," International Journal of Coal Science \& Technology, vol. 8, no. 1, pp. 64-76, 2021.

[4] J. L. Urai, C. J. Spiers, H. J. Zwart, and G. S. Lister, "Weakening of rock salt by water during long-term creep," Nature, vol. 324, no. 6097, pp. 554-557, 1986.

[5] J. Jin, S. Li, C. Song, X. Zhang, and X. Lv, "Ageing deformation of tailings dams in seasonally frozen soil areas under freezethaw cycles," Scientific Reports, vol. 9, no. 1, pp. 15033-15158, 2019.

[6] H. Xie, F. Gao, Y. Ju et al., "Theoretical and technological conception of the fluidization mining for deep coal resources," Journal of China Coal Society, vol. 42, no. 3, pp. 547-556, 2017.

[7] R. Azzam W and K. Nazir A, "Liquefaction mitigation using lateral confinement technique," Advances in Civil Engineering, vol. 12, no. 9, pp. 8-17, 2012.

[8] S. Basu, S. Pramanik, S. Dey, G. Panigrahi, and D. K. Jana, "Fire monitoring in coal mines using wireless underground sensor network and interval type-2 fuzzy logic controller," International Journal of Coal Science \& Technology, vol. 6, no. 2, pp. 274-285, 2019.

[9] T. Liu, "Experimental study on shear creep characteristics of mica schist," Geotechnical Investigation \& Surveying, vol. 48, no. 2, pp. 17-23, 2020.

[10] J. A. Hudson, "Effect of time on the mechanical behaviour of failed rock," Nature, vol. 232, no. 5307, pp. 185-186, 1971.

[11] Z.-L. He, Z.-D. Zhu, X.-H. Ni, and Z.-J. Li, "Shear creep tests and creep constitutive model of marble with structural plane," European Journal of Environmental and Civil Engineering, vol. 23, no. 11, pp. 1275-1293, 2017.

[12] W. Yao, B. Hu, H. Zhan, C. Ma, and N. Zhao, "A novel unsteady fractal derivative creep model for soft interlayers with varying water contents," KSCE Journal of Civil Engineering, vol. 23, no. 12, pp. 5064-5075, 2019.

[13] F. Zhang, Z. Jiang, and X. Yang, "Effect of pore water pressure on shear creep characteristics of serrate structural plane," Rock and Soil Mechanics, vol. 41, no. 9, pp. 2901-2912, 2020.

[14] L. Z. Wu, S. H. Li, P. Sun, R. Q. Huang, and B. Li, "Shear creep tests on fissured mudstone and an improved time-dependent model," Pure and Applied Geophysics, vol. 176, no. 11, pp. 4797-4808, 2019.

[15] Z. Zhang, S. Wu, T. Wang, P. Xin, and C. Liang, "Study on shear creep behavior and its model of mudstone in Tianshui, Gansu Province," Chinese Journal of Rock Mechanics and Engineering, vol. 38, no. S2, pp. 331-345, 2019.

[16] F. Zhang, Z. Jiang, X. Yang, and F. Shen, "Experimental and model study on shear creep of granite under freeze-thaw cycles," Rock and Soil Mechanics, vol. 41, no. 2, pp. 153-163, 2020.

[17] W. Chen, F. Li, J. Lei, H. Yu, and Y. Ma, "Study on creep characteristics of claystone under thermo-hydro-mechanical coupling," Rock and Soil Mechanics, vol. 41, no. 2, pp. 23-32, 2020 .
[18] T. Xu, Q. Xu, C.-A. Tang, and P. G. Ranjith, "The evolution of rock failure with discontinuities due to shear creep," Acta Geotechnica, vol. 8, no. 6, pp. 567-581, 2013.

[19] C. J. Jia, W. Y. Xu, R. B. Wang, S. S. Wang, and Z. N. Lin, "Experimental investigation on shear creep properties of undisturbed rock discontinuity in Baihetan Hydropower Station," International Journal of Rock Mechanics and Mining Sciences, vol. 104, no. 5, pp. 27-33, 2018.

[20] M. Gao, W. Jin, C. Zheng, and H. Zhou, "Real-time evolution and connectivity of mined crack network," Journal of China Coal Society, vol. 37, no. 9, pp. 1535-1540, 2012.

[21] J.-G. Wang, Q.-L. Sun, B. Liang, P.-J. Yang, and Q.-R. Yu, "Mudstone creep experiment and nonlinear damage model study under cyclic disturbance load," Scientific Reports, vol. 10, no. 1, pp. 9305-9311, 2020.

[22] J. Zuo, J. Wang, and Y. Jiang, "Macro/meso failure behavior of surrounding rock in deep roadway and its control technology," International Journal of Coal Science \& Technology, vol. 6, no. 3, pp. 301-319, 2019.

[23] G. A. Fermandois and B. F. Spencer, "Model-based framework for multi-axial real-time hybrid simulation testing," Earthquake Engineering and Engineering Vibration, vol. 16, no. 4, pp. 671-691, 2017.

[24] Y. Zhang, X. Wang, L. Zhao, J. Liu, N. Wang, and Y. Ding, "Mechanical performance study of the retractable pier column after stiffening," International Journal of Coal Science \& Technology, vol. 7, no. 4, pp. 725-739, 2020.

[25] M. Riock, "Suggested methods for determining the strength of rock materials in triaxial compression," International Journal of Rock Mechanics and Mining Science \& Geomechanics Abstracts, vol. 15, no. 2, pp. 47-51, 1978.

[26] B. Melbouci, R. Bahar, and B. Cambou, "Study of the behaviour of schist grains under crushing," Bulletin of Engineering Geology and the Environment, vol. 67, no. 2, pp. 209-218, 2008.

[27] S.-Q. Yang and B. Hu, "Creep and permeability evolution behavior of red sandstone containing a single fissure under a confining pressure of $30 \mathrm{MPa}$," Scientific Reports, vol. 10, no. 1, pp. 1900-1906, 2020.

[28] D. Ma, S. Kong, Z. Li, Q. Zhang, Z. Wang, and Z. Zhou, "Effect of wetting-drying cycle on hydraulic and mechanical properties of cemented paste backfill of the recycled solid wastes," Chemosphere, vol. 282, Article ID 131163, 2021.

[29] W. Cui, Q. Meng, Q. Feng, L. Zhou, Y. Cui, and W. Li, "Occurrence and release of cadmium, chromium, and lead from stone coal combustion," International Journal of Coal Science \& Technology, vol. 6, no. 4, pp. 586-594, 2019.

[30] J. Wang, B. Liang, and P. Yang, "Creep experiment and nonlinear disturbance creep model of gneiss under dynamic and static loads," Journal of China Coal Society, vol. 44, no. 1, pp. 199-205, 2019.

[31] F. Ghezzo, A. F. Starr, and D. R. Smith, "Integration of networks of sensors and electronics for structural health monitoring of composite materials," Advances in Civil Engineering, vol. 10, no. 2, pp. 13-21, 2010.

[32] H. O. Ozhan and E. Guler, "Critical tendon bond length for prestressed ground anchors in pullout performance tests conducted in sand," International Journal of Civil Engineering, vol. 16, no. 10, pp. 1329-1340, 2018.

[33] E. Hou, Q. Wen, Z. Ye, W. Chen, and J. Wei, "Height prediction of water-flowing fracture zone with a geneticalgorithm support-vector-machine method," International Journal of Coal Science \& Technology, vol. 7, no. 4, pp. 740-751, 2020. 
[34] H. Wu, D. Ma, A. J. S. Spearing, and G. Zhao, "Fracture response and mechanisms of brittle rock with different numbers of openings under uniaxial loading," Geomechanics and Engineering, vol. 25, no. 6, pp. 481-493, 2021.

[35] D. Ma, H. Duan, J. Liu, X. Li, and Z. Zhou, "The role of gangue on the mitigation of mining-induced hazards and environmental pollution: an experimental investigation," The Science of the Total Environment, vol. 664, no. 10, pp. 436-448, 2019.

[36] J. F. Shao, Q. Z. Zhu, and K. Su, "Modeling of creep in rock materials in terms of material degradation," Computers and Geotechnics, vol. 30, no. 7, pp. 549-555, 2003.

[37] K. Wu, Z. Shao, M. Sharifzadeh, S. Hong, and S. Qin, "Analytical computation of support characteristic curve for circumferential yielding lining in tunnel design," Journal of Rock Mechanics and Geotechnical Engineering, vol. 13, no. 2, pp. 1-13, 2021.

[38] M. Aubertin, D. E. Gill, and B. Ladanyi, "An internal variable model for the creep of rocksalt," Rock Mechanics and Rock Engineering, vol. 24, no. 2, pp. 81-97, 1991.

[39] D. N. Singh, N. Sivakugan, and S. K. Vanapalli, "Advances in instrumentation and monitoring in geotechnical engineering," Advances in Civil Engineering, vol. 11, no. 2, pp. 87-94, 2011.

[40] W. Marek, H. Natalia, and S. Adam, "Effect of flow rates of gases flowing through a coal bed during coal heating and cooling on concentrations of gases emitted and fire hazard assessment," International Journal of Coal Science \& Technology, vol. 7, no. 1, pp. 107-121, 2020.

[41] Z. Luo, J. Li, L. Wang, E. Assefa, and H. Deng, "Study on the creep characteristics of sandstone under coupled stress-water pressure," Periodica Polytechnica: Civil Engineering, vol. 63, no. 4, pp. 1038-1051, 2019.

[42] Z. Luo, J. Li, J. Qiao, Y. Zhang, and H. Deng, "Effect of the water-rock interaction on the creep mechanical properties of the sandstone rock," Periodica Polytechnica: Civil Engineering, vol. 62, no. 2, pp. 451-461, 2018.

[43] K. Wu, Z. Shao, and S. Qin, "An analytical design method for ductile support structures in squeezing tunnels," Archives of Civil and Mechanical Engineering, vol. 20, no. 3, pp. 91-99, 2020.

[44] K. Wu, Z. Shao, N. Zhao, S. Qin, and S. Hong, "Analytical assessment of coupled influences of surrounding rock reinforcement and deformation release on tunnel response," Geomechanics and Engineering, vol. 28, no. 1, pp. 1-9, 2021.

[45] L. Zhang and X. Wang, "Viscoelastic-plastic damage creep model for rock," Chinese Journal of Geotechnical Engineering, vol. 42, no. 6, pp. 1085-1092, 2020.

[46] X. Lian, H. Hu, T. Li, and D. Hu, "Main geological and mining factors affecting ground cracks induced by underground coal mining in Shanxi Province, China," International Journal of Coal Science \& Technology, vol. 7, no. 2, pp. 362-370, 2020. 